\title{
Transition of flow regime along a marine-terminating outlet glacier in East Antarctica
}

\author{
D. Callens ${ }^{1}$, K. Matsuoka ${ }^{2}$, D. Steinhage ${ }^{3}$, B. Smith ${ }^{4}$, E. Witrant ${ }^{5,1}$, and F. Pattyn ${ }^{1}$ \\ ${ }^{1}$ Laboratoire de Glaciologie, Université Libre de Bruxelles, Brussels, Belgium \\ ${ }^{2}$ Norwegian Polar Institute, Troms $\varnothing$, Norway \\ ${ }^{3}$ Alfred-Wegener-Institut Helmholtz-Zentrum für Polar- und Meeresforschung, Bremerhaven, Germany \\ ${ }^{4}$ Applied Physics Laboratory, University of Washington, Seattle, WA, USA \\ ${ }^{5}$ GIPSA-lab, Université Joseph Fourrier, Grenoble, France
}

Correspondence to: D. Callens (dcallens@ulb.ac.be)

Received: 10 September 2013 - Published in The Cryosphere Discuss.: 7 October 2013

Revised: 21 March 2014 - Accepted: 25 March 2014 - Published: 13 May 2014

\begin{abstract}
We present results of a multi-methodological approach to characterize the flow regime of West Ragnhild Glacier, the widest glacier in Dronning Maud Land, Antarctica. A new airborne radar survey points to substantially thicker ice $(>2000 \mathrm{~m})$ than previously thought. With a discharge estimate of $13-14 \mathrm{Gtyr}^{-1}$, West Ragnhild Glacier thus becomes of the three major outlet glaciers in Dronning Maud Land. Its bed topography is distinct between the upstream and downstream section: in the downstream section ( $<65 \mathrm{~km}$ upstream of the grounding line), the glacier overlies a wide and flat basin well below the sea level, while the upstream region is more mountainous. Spectral analysis of the bed topography also reveals this clear contrast and suggests that the downstream area is sediment covered. Furthermore, bed-returned power varies by $30 \mathrm{~dB}$ within $20 \mathrm{~km}$ near the bed flatness transition, suggesting that the water content at bed/ice interface increases over a short distance downstream, hence pointing to water-rich sediment. Ice flow speed observed in the downstream part of the glacier $\left(\sim 250 \mathrm{~m} \mathrm{yr}^{-1}\right)$ can only be explained through very low basal friction, leading to a substantial amount of basal sliding in the downstream $65 \mathrm{~km}$ of the glacier. All the above lines of evidence (sediment bed, wetness and basal motion) and the relatively flat grounding zone give the potential for West Ragnhild Glacier to be more sensitive to external forcing compared to other major outlet glaciers in this region, which are more stable due to their bed geometry (e.g. Shirase Glacier).
\end{abstract}

\section{Introduction}

The overall mass balance of the Antarctic ice sheet is dominated by a significant mass deficit in West Antarctica (Rignot et al., 2008; Pritchard et al., 2012). This is primarily due to thinning and acceleration of glaciers (e.g. Pine Island Glacier; Joughin et al., 2003) mainly driven by the loss of buttressing from ice shelves (Schoof, 2010). Concurrently, the trend in East Antarctica is weaker. The East Antarctic ice sheet (EAIS) is only losing mass slightly, as increased surface accumulation compensates mass loss through outlet glaciers (Shepherd et al., 2012). While Miles et al. (2013) observe a link between front migration and climate forcing, a significant widespread thinning trend along the pacific coast of the EAIS remains lacking.

Although East Antarctica is mainly continental, limited observations in Dronning Maud Land (DML), show that the ice sheet seaward of the inland mountains lies on a bed well below sea level (BEDMAP2; Fretwell et al., 2013) and most of the ice from the polar plateau is discharged through numerous glaciers in between coastal mountain ranges. The icedynamical consequences of such settings have yet to be explored. In this paper we investigate the marine boundary of such a glacier system draining the EAIS in DML.

The coastal region of DML is characterized by numerous outlet glaciers feeding into ice shelves (Fig. 1a). They are generally short in length but reach out to the continental shelf edge. The stability of these ice shelves is primarily ensured through the presence of ice rises and pinning points, making 

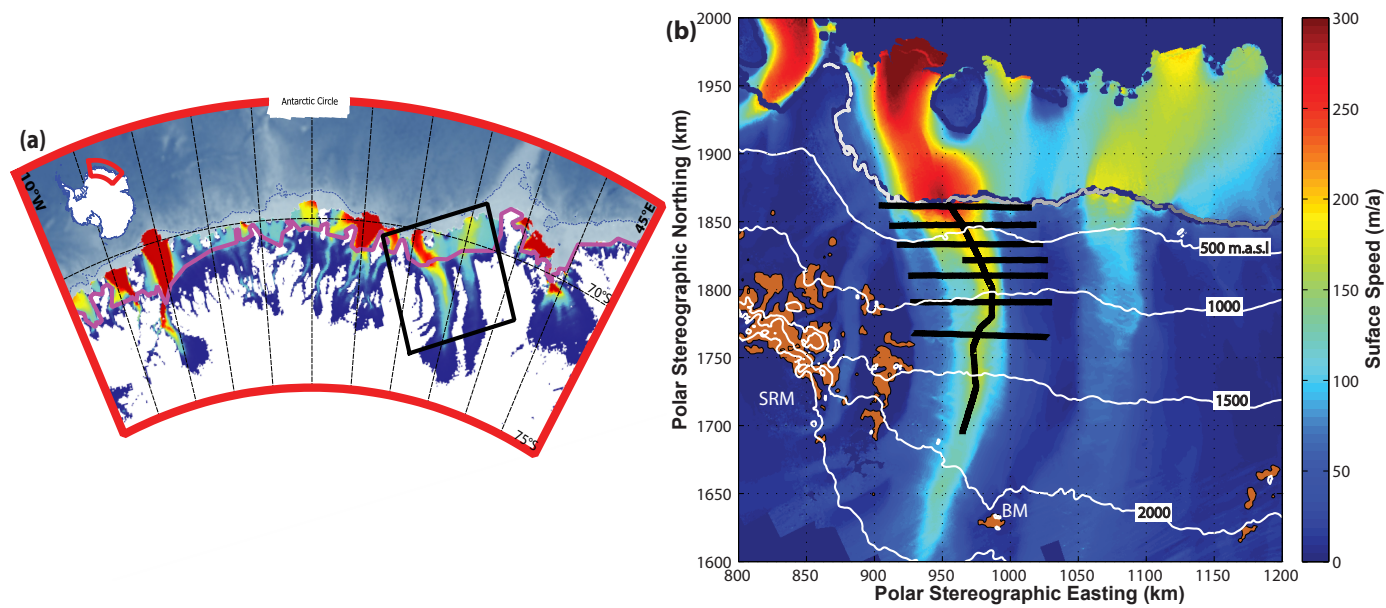

Fig. 1. Overview map of West Ragnhild Glacier, Dronning Maud Land, East Antarctica. (a) Dronning Maud Land. Ice flow speed is shown on the same scale as for panel (b) (but white when $<15 \mathrm{myr}^{-1}$; Rignot et al., 2011a). The grounding line is shown in purple (Bindschadler et al., 2011). Rock outcrops are shown in brown (SCAR, 2012). The square shows the $400 \mathrm{~km} \times 400 \mathrm{~km}$ area covered by the map on panel (b). The inset shows the coverage of panel (a). (b) West Ragnhild Glacier. Background colour shows the surface flow speed derived from satellite interferometry and speckle tracking. Contours show surface elevations at $500 \mathrm{~m}$ interval (Bamber et al., 2009). From west to east, the grounding line is defined on the basis of a pair of PALSAR images taken in 2007 (light grey) and two pairs of RADARSAT (middle grey and dark grey) taken in 2000 (Rignot et al., 2011b). Black lines are the longitudinal and transverse radar profiles. Rock outcrops as in (a). SRM and BM stand for Sør Rondane Mountains and Belgica Mountains, respectively.

the ice shelf locally grounded. Potential unpinning of these ice shelves would inevitably lead to ice shelf speed up, which makes them sensitive to marine forcing.

Of all glaciers in DML, West Ragnhild Glacier is the widest $(\approx 90 \mathrm{~km})$ and longest. Its ice flow speed is already $100 \mathrm{myr}^{-1} 250 \mathrm{~km}$ upstream from the grounding line (Fig. 1b). Based on the ice thickness data presented in this paper, we estimate the grounding line mass flux to be 13$14 \mathrm{Gtyr}^{-1}$, which constitutes roughly $10 \%$ of the total discharge from DML (Rignot et al., 2008). This is of the same order of magnitude as Shirase Glacier $\left(13.8 \pm 1.6 \mathrm{Gtyr}^{-1}\right.$; Pattyn and Derauw, 2002) and Jutulstraumen (14.2 $\mathrm{Gt} \mathrm{yr}^{-1}$; Høydal, 1996), the other two major outlet glaciers in the DML region.

The stability of West Ragnhild Glacier is most likely governed by the dynamics of its ice shelf which is dominated by two important ice rises and several pinning points. While rapid changes at the marine boundary have not yet been observed, Rignot et al. (2013) point to an exceedance of basal melt (underneath the ice shelf and at the grounding line) over calving for several ice shelves in DML (including Roi Baudouin Ice Shelf, downstream of West Ragnhild Glacier). Melting at the grounding line $50 \mathrm{~km}$ west from West Ragnhild Glacier has been reported in Pattyn et al. (2012), but its magnitude is of the orders of tens of centimetres per year.

To understand what makes West Ragnhild Glacier one of the three most significant mass outputs in DML, we investigate its basal conditions using satellite remote sensing, airborne radar and ice sheet modelling. First, radar analysis reveals the geometry of the bed. Second, we characterize the roughness of the bed and its reflectivity through spectral and bed-returned power analyses, which inform us of the nature of the bed as well as of the water content. Finally, we estimate the basal friction through inverse modelling to reconstruct basal motion. We subsequently discuss the consequences of a marine-terminating East Antarctic outlet glacier, characterized by a wet sediment and dominated by basal motion/sliding.

\section{Data acquisition}

Ice flow surface velocities are generated based on RADARSAT data acquired during the austral spring of 2000. These velocities combine phase and speckle tracking offsets, using methods that minimize the error of the final combined product (Joughin, 2002). The resolution of the velocity data is $500 \mathrm{~m} \times 500 \mathrm{~m}$, covering the main trunk of West Ragnhild Glacier and its vicinity (Fig. 1b).

The airborne radio echo sounding survey was carried out on West Ragnhild Glacier during the austral summer 20102011, resulting in one longitudinal (along-flow) profile and seven transverse profiles (Fig. 1b). The radar system employed a $150 \mathrm{MHz}$ centre frequency and transmitted bursts of 600 and $60 \mathrm{~ns}$ duration, toggling between the two bursts (Nixdorf et al., 1999; Steinhage et al., 2001). The system recorded at a rate of $20 \mathrm{~Hz}$. For further signal-to-noise improvement, the data of same burst length were stacked tenfold, resulting in a horizontal resolution of $80 \pm 20 \mathrm{~m}$. We identified the bed echo along $91 \%$ of the entire survey 


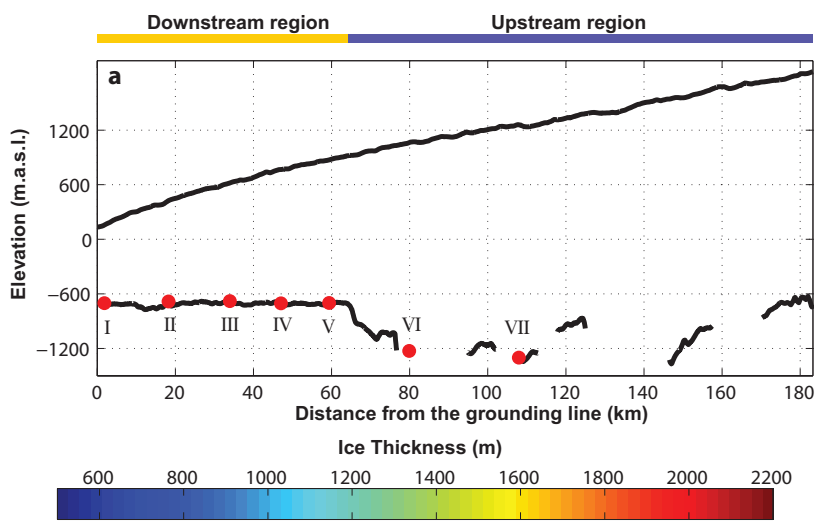

b
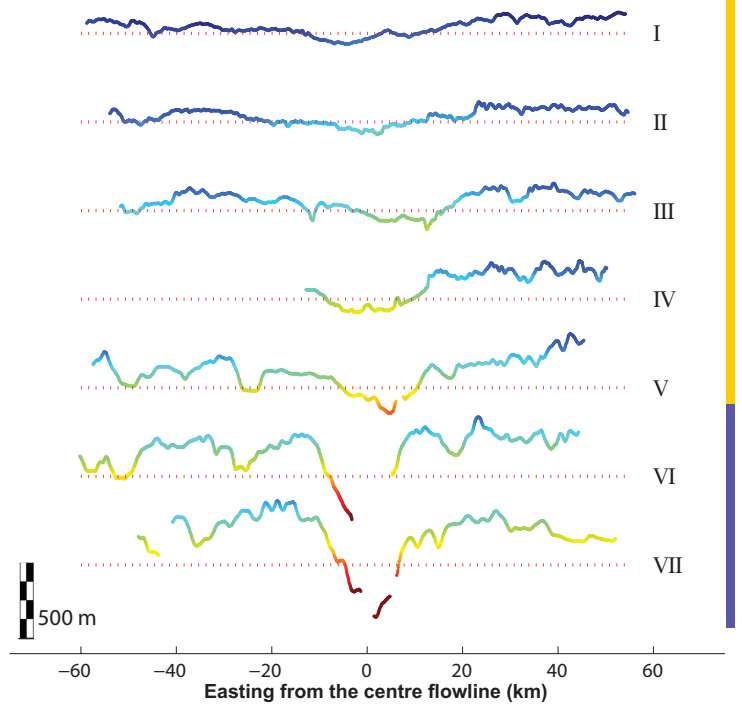

Fig. 2. Radar data. (a) Ice and bed topography along the central flowline. The red circles are the locations of the cross profiles. (b) Bed topography (ordinate) and ice thickness (colour) measured across the flow. The red dotted lines show the isodepth of $600 \mathrm{~m}$ b.s.l., the approximate elevation of the flat basin measured along the centre flowline (a) and the reference for each profile.Transverse profiles are numbered from I to VII on both panels. The yellow and blue line illustrates our understanding of the downstream and upstream region.

(Fig. 2). Most sections lacking a bed echo are shorter than $\sim 10 \mathrm{~km}$ (the maximum data gap is $20 \mathrm{~km}$ ). Adjacent regions to these data gaps slope down steeply toward the data gaps. Therefore, the data gaps probably correspond to a deep bed and thick ice, causing an increased radar signal attenuation, and hence loss of signal.

Ice thickness was derived using a constant radio wave propagation speed of $168 \mathrm{~m} \mathrm{~s}^{-1}$. Surface elevation was obtained by laser altimetry from the aircraft, and bed elevation was subsequently derived by subtracting the ice thickness from the surface elevation. We applied the geoid height of $20 \mathrm{~m}$ above the EGM96 ellipsoid (Rapp, 1997) to derive the surface and bed elevations relative to sea level.

\section{Mapping the subglacial topography}

Compared to older data sets of Antarctic bedrock topography (e.g. BEDMAP; Lythe et al., 2001), our new radar survey reveals a significantly different picture ${ }^{1}$. The survey highlights a marked contrast in bed topography (Fig. 2). Between the Sør Rondane and Belgica Mountains, ice flows in a deeply incised valley, $\sim 20 \mathrm{~km}$ wide, lying $\sim 1000 \mathrm{~m}$ below sea level at the two uppermost transverse profiles (Fig. 2b). The bed topography is rather variable here, fluctuating between 1200 and $800 \mathrm{~m}$ b.s.l. Further downstream, bedrock elevation increases rapidly (more than $500 \mathrm{~m}$ within $10 \mathrm{~km}$ distance) up to a flat subglacial lowland lying around $600 \mathrm{~m}$ b.s.l. This can be observed on both the longitudinal (Fig. 2a) and cross profiles (Fig. 2b). The elevation of this lowland varies less than $50 \mathrm{~m}$ locally, so the lowland is much flatter than the landward valley between Sør Rondane and Belgica Mountains. The amplitude of the local elevation variations increases sharply between cross profiles 4 and 5 as we reach the piedmont of the Sør Rondane Mountains. This is also the zone where we find the onset of the subglacial valley, described earlier.

\section{Spectral analysis of bed topography}

\subsection{Bed roughness index}

One way to quantitatively characterize the above-described bed conditions is to calculate bed roughness. The bed roughness index RI is obtained by applying a fast Fourier transform (FFT) to the bed elevation within a moving window (Taylor et al., 2004):

$\mathrm{RI}=\int_{f_{\min }}^{f_{\max }} \frac{|X[f]|^{2}}{N_{\mathrm{T}} \Delta x} \mathrm{~d} f$,

where $f_{\min }=1 /\left(N_{\mathrm{T}} \Delta x\right), f_{\max }=1 /(2 \Delta x), N_{\mathrm{T}}=2^{n}$ is the number of data points in the window, $\Delta x$ is the sampling interval ( $100 \mathrm{~m}$ in our case) and where

$X[f]=\sum_{d=1}^{N_{\mathrm{T}}} x(d) e^{\frac{2 \pi i}{N_{\mathrm{T}}}(d-1)(f-1)}$.

Equation (2) is the definition of the FFT for a dataset $x(d)$ with index $d$ in the range $1 \leq d \leq N_{\mathrm{T}}$, and $X[f]$ is the same data set in the frequency domain with index $f$ in the range $f_{\min } \leq f \leq f_{\max }$. In other words, the bed roughness index RI is the integral of the resultant power spectrum within each of the moving windows.

We first resample the radar-derived bed topography $(80 \pm 20 \mathrm{~m}$ intervals) with a fixed $(100 \mathrm{~m})$ interval. We then detrend the measured bed elevation in each moving window,

\footnotetext{
${ }^{1}$ The data collected for this paper are incorporated in the recently published BEDMAP2 data set (Fretwell et al., 2013).
} 
which is required to be able to perform an FFT. The method is applied within a $2^{n}$ data point window. Several authors recommend $n \geq 5$ (Taylor et al., 2004; Bingham and Siegert, 2009; Rippin et al., 2011). By using $n=6$ we are able to analyse roughness over wavelengths ranging from 200 up to $6400 \mathrm{~m}$.

\subsection{Results}

The longitudinal bed profile (Fig. 2) reveals two distinct areas: a flat area (between the grounding line and $65 \mathrm{~km}$ upstream) and an intersected subglacial relief typical of subglacial mountain ranges. The transition between them occurs within $10 \mathrm{~km}$. The bed roughness index RI is capable of quantifying this difference (Figs. 3 and 4a). While the two regions are still quite distinct, the transition of roughness from one to the other is more gradual than expected from visual interpretation. For the downstream cross profiles (I-III), the bed roughness is approximately constant, pointing to a wide and relatively smooth lowland. Following the analysis of Bingham and Siegert (2009), the flat and smooth area in the downstream section of the West Ragnhild Glacier may therefore very well be overlain by marine sediment. According to the further upstream profiles (IV-V), the bed is rougher away from the current glacier flowline (longitudinal radar profile). The low roughness area is therefore restricted to the zones of fast ice flow. Once outside this section, bed roughness indices increase, pointing to a rougher surface (VI-VII).

\section{Analysis of bed-returned power}

\subsection{Analytical setup}

To further examine the spatial distribution of basal conditions, we analyse the radar power returned from the bed, hereafter called BRP. The geometrically corrected BRP, $\mathrm{BRP}^{\mathrm{c}}$, can be seen as a proxy for bed reflectivity if englacial effects do not vary along the radar profile (Matsuoka, 2011). The BRP ${ }^{\mathrm{c}}$ is affected by both englacial attenuation $L$ and bed reflectivity $R$. In the decibel scale, $[x]_{\mathrm{dB}}=10 \log _{10}(x)$, this relationship can be written as

$$
\begin{aligned}
{\left[\mathrm{BRP}^{\mathrm{c}}\right]_{\mathrm{dB}} } & =[\mathrm{BRP}]_{\mathrm{dB}}+10 \log _{10}\left(h+\frac{H}{n}\right)^{2}, \\
& \simeq[R]_{\mathrm{dB}}-[L]_{\mathrm{dB}} .
\end{aligned}
$$

The geometrically corrected bed-returned power $\mathrm{BRP}^{\mathrm{c}}$ can be calculated based on the measured BRP returned from the bed and a geometric factor defined by $(h+H / n)^{2}$. Here, $h$ is the height of the aircraft above the glacier surface, $H$ is the ice thickness (distance between the surface and the bed of the ice mass), and $n$ is the refraction index of the ice ( $\sim 1.8$; Matsuoka et al., 2012). The BRP ${ }^{c}$ is then normalized to the mean of the observed values.

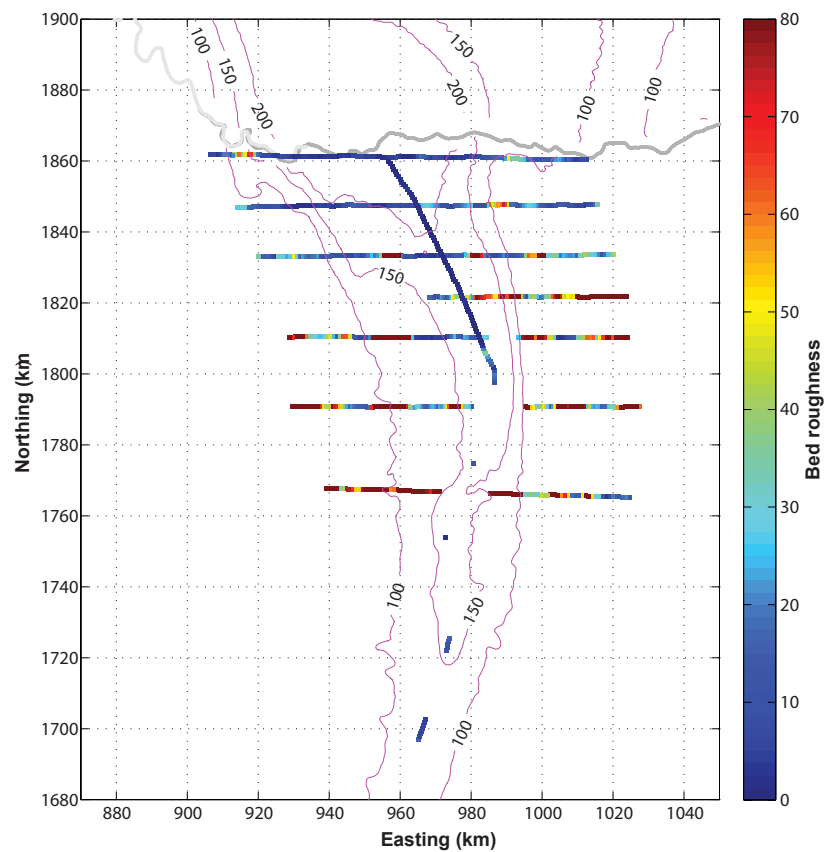

Fig. 3. Bed roughness analysis. Bed roughness index of the basal topography (colour) calculated for wavelengths ranging from 200 to $6400 \mathrm{~m}$. The grounding line is the same as in Fig. 1b. Short legs of absent bed echoes result in long gaps in the estimated bed roughness indices due the window-based calculation of the bed roughness index. Larger RI corresponds to rougher bed. Contour lines represent surface speed $\left(\mathrm{ma}^{-1}\right)$.

One has to note that effects of temporal changes in the instrumental characteristics and of ice crystal alignments are ignored in Eq. (3). Englacial attenuation has contributions from pure ice and chemical constituents included in the glacier ice, both of which depend exponentially on ice temperature.

We estimate attenuation $L$ using Eqs. (4)-(6) listed below (Matsuoka et al., 2012). The depth-averaged attenuation rate $\langle N\rangle$ is derived from the depth profile of the attenuation rate $N(z)$, i.e.,

$[L]_{\mathrm{dB}}=\int_{0}^{H} N(z) \mathrm{d} z$.

The attenuation profile $N(z)$ is proportional to local ice conductivity $\sigma$ :

$N(z)=\frac{1000\left(10 \log _{10} e\right)}{c \varepsilon_{0} \sqrt{\varepsilon}} \sigma(z) \approx 0.914 \sigma(z)$,

where $c$ is the wave velocity in vacuum, $\varepsilon_{0}$ is the permittivity of free space and $\varepsilon$ is the relative permittivity of the ice. Since we focus only on the contribution of pure ice to the attenuation, conductivity depends only on temperature through 


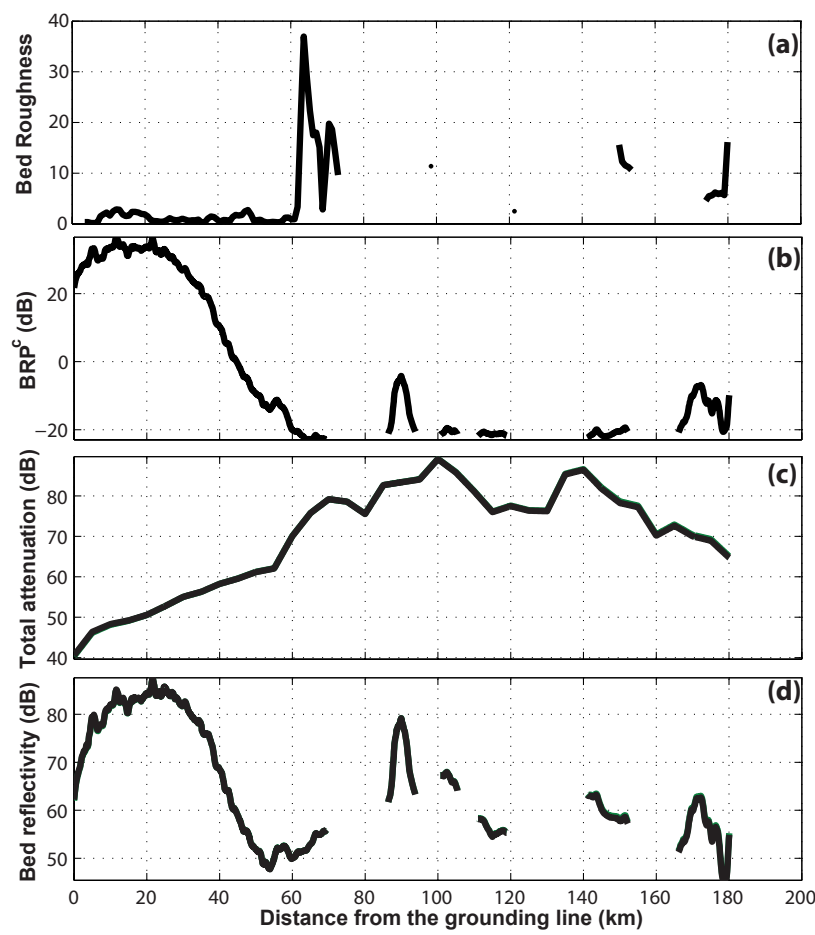

Fig. 4. Subglacial conditions along the central flowline. (a) Bed roughness index RI; (b) geometrically corrected bed-returned power $\mathrm{BRP}^{\mathrm{c}}$; (c) englacial attenuation $L ;$ (d) bed reflectivity $R$.

an Arrhenius-type relationship.

$\sigma=\sigma_{0} \exp \left[-\frac{E_{0}}{k}\left(\frac{1}{T(z)}-\frac{1}{T_{\mathrm{r}}}\right)\right]$

where $\sigma_{0}=15.4 \mu \mathrm{S} \mathrm{m}^{-1}$ is the pure-ice conductivity at the reference temperature $T_{\mathrm{r}}=251 \mathrm{~K}, T(z)$ is the vertical profile of temperature, $E_{0}=0.33 \mathrm{eV}$ is the activation energy and $k=8.617 \times 10^{-5} \mathrm{eV} \mathrm{K}^{-1}$ is the Boltzmann constant (Matsuoka et al., 2012).

Englacial temperatures $T(z)$ for the attenuation model (Eq. 6) are calculated using a two-dimensional thermomechanical higher-order model (Pattyn, 2002, 2003). Details of this approach are given in Matsuoka et al. (2012). We use a geothermal heat flux of $42 \mathrm{~mW} \mathrm{~m}^{-2}$ as lower boundary condition. However, as shown in Matsuoka et al. (2012), the exact choice of geothermal heat flux will not affect the modelled englacial attenuation since the bed in the surveyed domain is predicted to be at the pressure melting point everywhere even with a flux as low as $42 \mathrm{~mW} \mathrm{~m}^{-2}$. Once the bed reaches pressure melting point, additional geothermal and shear heating have virtually no impact on ice temperature, hence on englacial attenuation (Matsuoka, 2011). Therefore, the estimated along-flow patterns of the attenuation and bed reflectivity are robust regardless of the uncertainties in geothermal heat flux. Figure $4 \mathrm{c}$ shows $[L]$ along the longitudinal profile.
Although the chemical contribution to attenuation can nearly equal the pure-ice contribution near the coast (Matsuoka et al., 2012), the lack of observation forces us to ignore its contribution and to use only the pure-ice contribution to estimate englacial attenuation. Furthermore, MacGregor et al. (2007) and Matsuoka et al. (2012) showed that the relative importance of impurities contribution decreases as temperature increases. The modelling reveals a mean attenuation rate from pure ice between 20.2 and $23.1 \mathrm{~dB} \mathrm{~km}^{-1}$. For this range of value, Matsuoka et al. (2012) determine that chemical contribution is less than the fifth of the pure ice contribution.

\subsection{Results}

In the upstream valley, $\mathrm{BRP}^{\mathrm{c}}$ remains relatively low $(-20 \mathrm{~dB})$ and varies little (several $\mathrm{dB})$ except at two sites where $\mathrm{BRP}^{\mathrm{c}}$ shows anomalous features $(90 \mathrm{~km}$ and $170 \mathrm{~km}$ upstream from the grounding line; Fig. 4b). Further downstream, $\mathrm{BRP}^{\mathrm{c}}$ increases by $\sim 50 \mathrm{~dB}$ within $20 \mathrm{~km}$, over which the ice thins only by $\sim 200 \mathrm{~m}$ (Fig. 2).

To clarify contributions of the bed reflectivity on $\mathrm{BRP}^{\mathrm{c}}$, we estimate the englacial attenuation using the predicted temperature (Fig. 4c). Attenuation decreases $\sim 20 \mathrm{~dB}$ within $10 \mathrm{~km}$ at $65 \mathrm{~km}$ upstream from the grounding line due to a decrease in ice thickness. Further downstream, attenuation gradually decreases by $20 \mathrm{~dB}$ over $50 \mathrm{~km}$, which is probably more related to the changes in ice thickness than to changes in depth-averaged attenuation rate $\langle N\rangle$. To retrieve the actual bed reflectivity, we estimated bed reflectivity from BRP $^{\mathrm{c}}$ and englacial attenuation using Eq. (3). The corresponding estimated bed reflectivity rapidly increases, approaching the grounding line at $40-50 \mathrm{~km}$, from where it varies little within the last $\sim 30 \mathrm{~km}$ (Fig. $4 \mathrm{~d}$ ). The high bed reflectivity in the zone immediately upstream of the grounding line may eventually point to wet bed conditions. This high bed reflectivity is not directly related to the smoother bed interface because $\mathrm{RI}$ is calculated for the wavelengths longer than $200 \mathrm{~m}$ but the reflectivity is affected by the bed smoothness in the scale of several wavelengths of the radio wave ( $5 \mathrm{~m}$ for this study). In the next section, we will investigate whether wet basal conditions are likely or not.

\section{Ice flow modelling}

\subsection{Model setup}

Velocity data show that West Ragnhild Glacier accelerates steadily towards the grounding line (Fig. 5). In this section,using an ice flow model, we will infer the required spatial distribution of basal friction (or, inversely, slipperiness) to match modelled ice flow velocities to the satelliteobserved ones. The most common method is an inversion method in which a friction parameter is spatially optimized in 

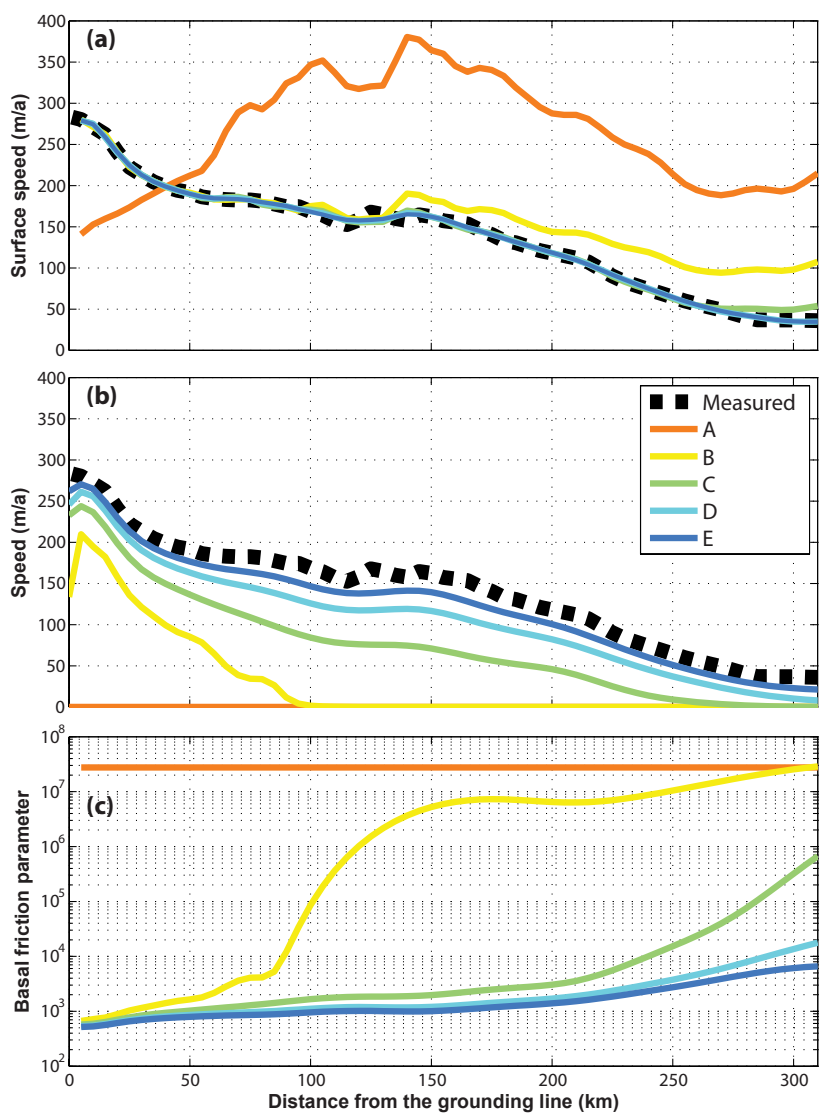

Fig. 5. (A) Observed surface flow speed (dashed black line) and optimized surface flow speed profiles along the central flowline of West Ragnhild Glacier; (B) Basal ice flow speed according to the optimization and compared to the satellite-observed surface flow speed (as in panel $\mathbf{A}$ ); (C) Basal friction $\beta^{2}$ along the flowline.

order to minimize the misfit between modelled and observed velocities (MacAyeal, 1992, 1993; Arthern et al., 2010).

As a forward model we apply a simple ice flow model to calculate the ice flow field along the central flowline of Western Ragnhild Glacier, based on the shallow-ice approximation (SIA). In the vertically integrated case, the SIA surface velocity $(u(s))$ is then given by

$u(s)=u(b)+\frac{2 \bar{A}}{n+1} H\left|\tau_{\mathrm{d}}\right|^{n-1} \tau_{\mathrm{d}}$,

where $\tau_{\mathrm{d}}=-\rho g H \frac{\partial \mathrm{s}}{\partial x}$ is the driving stress, and $u(b)=\beta^{-2} \tau_{\mathrm{d}}$ is the basal velocity according to a viscous sliding law (Pattyn et al., 2008). Other parameters in Eq. (7) are $\bar{A}$ and $n=3$, the vertically integrated temperature-dependent flow parameter and the exponent in Glen's flow law, respectively; $\beta$ is the basal friction, $\rho$ is the ice density, $g$ is the gravitational acceleration, $H$ is the ice thickness, and $s$ is the surface elevation. For a flowline stretching from the ice divide (Dome Fuji) to the grounding line, boundary conditions for Eq. (7) are a zero upstream velocity and a fixed surface velocity at the edge of our profile of $u=300 \mathrm{myr}^{-1}$, according to observations.

Since an SIA model does not take into account longitudinal stress gradients, spurious high-frequency variability in the velocity field is to be expected when the surface of the ice sheet is not supposed to relax to the imposed stress field. Especially small variations in surface slope may lead to a large variability in velocity, due to its dependence on the power of $n$. To prevent this, surface gradients are calculated over a distance of several ice thicknesses (Kamb and Echelmeyer, 1986; Rabus and Echelmeyer, 1997).

The main unknown in Eq. (7) is the basal velocity field, which is initialized with a high value of basal friction $\left(\beta^{2}=\right.$ $10^{7}$ ), corresponding to conditions of ice frozen to the bed. We then invoke an optimization procedure to determine the spatial distribution of $\beta^{2}$ so that the modelled surface velocity $\left(u_{\mathrm{s}}^{\mathrm{m}}\right)$ matches the observed one $\left(u_{\mathrm{s}}^{\mathrm{o}}\right)$. This is formulated as a least-squares problem for which we seek $\beta^{2}$ that minimizes the following objective function:

$J\left(\hat{\beta^{2}}\right)=\sum_{i=1}^{n_{\mathrm{o}}}\left\|u_{\mathrm{s}}^{\mathrm{o}}(i)-u_{\mathrm{s}}^{\mathrm{m}}\left(\hat{\beta}^{2}, i\right)\right\|^{2}$.

The minimization problem is solved in a vector-valued approach. The vector containing the squared errors of the basal velocity mismatch is provided to the algorithm that calculates the flow field according to Eq. (7). The error vector is used to compute a preconditioned conjugate gradient (computed numerically using small variations in $\beta^{2}$ along the flowline). The subspace trust region method based on the interiorreflective Newton method (trust-region-reflective algorithm) described by Coleman and $\mathrm{Li}(1994,1996)$ then determines the modified $\beta^{2}$-profile for the next iteration. The iterations stop when the change in $J\left(\hat{\beta}^{2}\right)$ is below an arbitrarily small threshold.

We add two constraints to $\beta^{2}$. It has to be positive and, as we expect the basal friction pattern to be continuous in space (i.e. $u(b)$ is continuously differentiable), the spatial pattern is expressed in terms of summations of Legendre polynomials. Such polynomials have the interesting property that they form an orthogonal basis and lead to a better conditioning of the nonlinear optimization problem, thus necessitating fewer iterations to converge to the optimal solution. We use these polynomials to describe the spatial distribution of $\beta^{2}$ along the flowline. We use polynomials up to degree 35 . At this stage, we reach convergence, which means that increasing the polynomial degree does not reduce the error function any further.

The surface and bed topography within the survey domain are taken from our data. Beyond this domain, bed and surface topography are taken from both BEDMAP (Lythe et al., 2001) and Bamber et al. (2009). The resulting profile is similar to the one resampled directly from BEDMAP2 (Fretwell et al., 2013), since our ice thickness data have been included. Short gaps within the retrieved bed echoes are 
linearly interpolated; the length of such gaps is typically less than several ice thicknesses, so that the large-scale flow fields are hardly affected by this choice. Longer gaps $(>10 \mathrm{~km})$ were interpolated in the same way. Bed topography uncertainties associated with the longer data gaps introduces flow speed uncertainties in the most upstream area and are sufficiently far away from our region of interest.

\subsection{Results}

To correct for the unknown deformational velocity, we performed the optimization procedure for different values of the vertically integrated flow parameter $\bar{A}$. Each of the values corresponds to mean ice temperatures of $-2,-4,-5$, -10 and $-15^{\circ} \mathrm{C}$ (Cuffey and Paterson, 2010). Amongst the five different flow parameters depicted in Fig. 5, case A corresponds to the warmest (softest) ice $\left(-2{ }^{\circ} \mathrm{C}\right)$, and predicts higher ice flow speeds due to ice deformation along the whole flowline compared to the observed ones. For this value, the optimization procedure fails, as the model cannot allow "negative" basal velocities. Not only is the ice too soft (hence flows too fast), the pattern of the deformational velocity does not match the observed velocity profile.

Cases B to E reveal a good match of the modelled velocities with the observed ones. For each decrement in ice temperature, the ice gets stiffer and the amount of basal sliding along the profile becomes more important. Therefore, cases $\mathrm{D}$ and $\mathrm{E}$ correspond to much colder (stiffer) ice $(-10$ and $-15^{\circ} \mathrm{C}$, respectively) and predict deformational velocities that are too small, so that basal sliding takes up the majority of the velocity along the profile.

The corresponding pattern of $\beta^{2}$ is, with the exception of case A, very similar for all simulations: it reveals a relatively high friction inland and a low friction in the area $100 \mathrm{~km}$ upstream from the grounding line. Over the upstream section of the longitudinal profile, ice motion is essentially governed by internal deformation. All experiments show that basal motion is dominant only in the downstream region.

\section{Discussion and conclusions}

Prior to our study, only two glaciers were considered as important contributors to the discharge of ice from DML, i.e. Jutulstraumen and Shirase Glacier, and both have been the subject of more interest in the past (e.g. Høydal, 1996; Pattyn and Derauw, 2002). Despite their fast flow (the grounding line velocity of Shirase Glacier is $>2000 \mathrm{~m} \mathrm{yr}^{-1}$ ), they each discharge approximately $10 \%$ of the total snow accumulation of this part of the ice sheet (Rignot et al., 2008). Both glaciers are topographically constrained and characterized by a highly convergent flow regime. They also terminate in a relatively narrow trunk. From an ice-dynamical viewpoint, Shirase Glacier is a relatively stable feature, as its grounding line cannot retreat over a distance larger than 5 to $10 \mathrm{~km}$, since the bedrock rapidly rises above sea level from the present position of the grounding line (Pattyn, 1996, 2000; Pattyn and Derauw, 2002). Such conditions make an outlet glacier less prone to dynamic grounding line retreat and significant mass loss due to dynamic changes in the ice shelf.

Taking into consideration West Ragnhild Glacier definitely changes the discharge picture in DML. Indeed, based on the thickness data across the grounding line in conjunction with satellite-observed ice flow velocities, its discharge (13-14 $\left.\mathrm{Gt} \mathrm{yr}^{-1}\right)$ is comparable to the discharge of Jutulstraumen and Shirase Glacier. Nonetheless, the ice flow velocities of West Ragnhild Glacier are relatively low. Ice flow speed is $>100 \mathrm{myr}^{-1}$ at $100 \mathrm{~km}$ upstream of the grounding line and up to $250 \mathrm{myr}^{-1}$ at the grounding line (Fig. 1). The reason for such low values is ice shelf buttressing by two major ice rises within the Roi Baudouin Ice Shelf, slowing down the flow upstream. While according to Rignot et al. (2008), the area seemed to be in balance, a significant imbalance is currently observed in the grounding zone of West Ragnhild Glacier and along the grounding line of the Roi Baudouin Ice Shelf (Rignot et al., 2013), which is in line with direct observations (Pattyn et al., 2012).

Despite present-day stable conditions, the analysis presented in this paper clearly demonstrates that West Ragnhild Glacier (i) is an important outlet glacier, (ii) is marine terminating with a grounding line $600-700 \mathrm{~m}$ b.s.l., and (iii) has a downstream section that is smooth, sediment covered and water saturated in the downstream area. Beside data evidence, inverse modelling allows the conclusion that decreasing basal friction leads to an increasing basal velocity towards the grounding line. Using two different kinds of evidence, we demonstrate that the bed/ice interface plays a dominant role in the acceleration of West Ragnhild Glacier toward the grounding line.

Given the fact that the smooth bed is also flat and horizontal and devoid of distinct lateral constraints, the grounding line is potentially capable of advancing and retreating across a substantial area. According to theoretical considerations (Schoof, 2007), a grounding line retreat may be expected if sudden changes occur at the seaward side. The close proximity of the DML ice shelves to the margin of the continental shelf (Timmermann et al., 2010, and Fig. 1a) could potentially allow relatively warm water from the abyssal plains to circulate under the shelf, leading to significant sub-shelf melting (e.g. Smedsrud et al., 2006). Unpinning of the ice shelf could therefore lead to grounding line retreat due to increased flow speed, hence increased dynamic mass loss, in line with recent observations (Rignot et al., 2013). New geophysical data presented in this paper highlight such a possibility in West Ragnhild Glacier. 
Acknowledgements. The radar survey was conducted by the Alfred Wegener Institute with further logistical support from the Princess Elisabeth Station (Belgian Antarctic Research Expedition, BELARE), and funded by the European Facilities for Airborne Research (EUFAR). D. Callens is funded through a FNRS-FRIA fellowship (Fonds de la Recherche Scientifique) and received an Yggdrasil mobility grant (Research Council of Norway). This work is in part supported by the Centre for Ice, Climate and Ecosystems (ICE) at the Norwegian Polar Institute.

Edited by: C. R. Stokes

\section{References}

Arthern, R. J. and Gudmundsson, G. H.: Initialisation of Ice-Sheet Forecasts viewed as an Inverse Robin Problem, J. Glaciol., 56, 527-533, 2010.

Bamber, J. L., Gomez-Dans, J. L., and Griggs, J. A.: A new 1 km digital elevation model of the Antarctic derived from combined satellite radar and laser data - Part 1: Data and methods, The Cryosphere, 3, 101-111, doi:10.5194/tc-3-101-2009, 2009.

Bindschadler, R. A., Choi, H., and ASAID Collaborators: HighResolution Image-derived Grounding and Hydrostatic Lines for the Antarctic Ice Sheet, Digital media, National Snow and Ice Data Center, Boulder, Colorado, USA, 2011.

Bingham, R. G. and Siegert, M. J.: Quantifying subglacial bed roughness in Antarctica: implications for ice-sheet dynamics and history, Quaternary Sci. Rev., 28, 223-236, 2009.

Coleman, T. and Li, Y.: On the Convergence of Reflective Newton Methods for Large-Scale Nonlinear Minimization Subject to Bounds, Math. Program., 67, 189-224, 1994.

Coleman, T. and Li, Y.: An Interior, Trust Region Approach for Nonlinear Minimization Subject to Bounds, SIAM J. Optimiz., 6, 418-445, 1996.

Cuffey, K. and Paterson, W. S. B.: The Physics of Glaciers, 4th Edn., Elsevier, New York, 2010.

Fretwell, P., Pritchard, H. D., Vaughan, D. G., Bamber, J. L., Barrand, N. E., Bell, R., Bianchi, C., Bingham, R. G., Blankenship, D. D., Casassa, G., Catania, G., Callens, D., Conway, H., Cook, A. J., Corr, H. F. J., Damaske, D., Damm, V., Ferraccioli, F., Forsberg, R., Fujita, S., Gim, Y., Gogineni, P., Griggs, J. A., Hindmarsh, R. C. A., Holmlund, P., Holt, J. W., Jacobel, R. W., Jenkins, A., Jokat, W., Jordan, T., King, E. C., Kohler, J., Krabill, W., Riger-Kusk, M., Langley, K. A., Leitchenkov, G., Leuschen, C., Luyendyk, B. P., Matsuoka, K., Mouginot, J., Nitsche, F. O., Nogi, Y., Nost, O. A., Popov, S. V., Rignot, E., Rippin, D. M., Rivera, A., Roberts, J., Ross, N., Siegert, M. J., Smith, A. M., Steinhage, D., Studinger, M., Sun, B., Tinto, B. K., Welch, B. C., Wilson, D., Young, D. A., Xiangbin, C., and Zirizzotti, A.: Bedmap2: improved ice bed, surface and thickness datasets for Antarctica, The Cryosphere, 7, 375-393, doi:10.5194/tc-7-3752013, 2013

Høydal, Ø. A.: A force-balance study of ice flow and basal conditions of Jutulstraumen, Antarctica, J. Glaciol., 42, 413-425, 1996.

Joughin, I.: Ice-sheet velocity mapping: a combined interferometric and speckle-tracking approach, Ann. Glaciol., 34, 195-201, 2002.
Joughin, I., Rignot, E., Rosanova, C. E., Lucchitta, B. K., and Bohlander, J.: Timing of Recent Accelerations of Pine Island Glacier, Antarctica, Geophys. Res. Lett., 30, 1706, doi:10.1029/2003GL017609, 2003.

Kamb, B. and Echelmeyer, K. A.: Stress-gradient Coupling in Glacier Flow: 1. Longitudinal Averaging of the Influence of Ice Thickness and Surface Slope, J. Glaciol., 32, 267-298, 1986.

Lythe, M. B., Vaughan, D. G., and BEDMAP consortium: BEDMAP: a new ice thickness and subglacial topographic model of Antarctica, J. Geophys. Res., 106, 11335-11351, 2001.

MacAyeal, D. R.: The basal stress distribution of Ice Stream E, Antarctica, inferred by control methods, J. Geophys. Res., 97, 595-603, 1992.

MacAyeal, D. R.: A Tutorial on the Use of Control Methods in IceSheet Modeling, J. Glaciol., 39, 91-98, 1993.

MacGregor, J. A., Winebrenner, D. P., Conway, H.,Matsuoka, K., Mayewski, P. A., and Clow, G. D.: Modeling englacial radar attenuation at Siple Dome, West Antarctica, using ice chemistry and temperature data, J. Geophys. Res., 112, F03008, doi:10.1029/2006JF000717, 2007.

Matsuoka, K.: Pitfalls in radar diagnosis of ice-sheet bed conditions: Lessons from englacial attenuation models, Geophys. Res. Lett., 38, L05505, doi:10.1029/2010GL046205, 2011.

Matsuoka, K., MacGregor, J. A., and Pattyn, F.: Predicting radar attenuation within the Antarctic ice sheet, Earth Planet. Sc. Lett., 359-360, 173-183, 2012.

Miles, B. W. J., Stokes, C. R., Vieli, A., and Cox, N. J.: Rapid, climate-driven changes in outlet glaciers on the Pacific coast of East Antarctica, Nature, 500, 563-566, 2013.

Nixdorf, U., Steinhage, D., Meyer, U., Hempel, L., Jenett, M., Wachs, P., and Miller, H.: The newly developed airborne radioecho sounding system of the AWI as a glaciological tool, Ann Glaciol., 29, 231-238, 1999.

Pattyn, F.: Numerical modelling of a fast-flowing outlet glacier: experiments with different basal conditions, Ann. Glaciol., 23, 237-246, 1996.

Pattyn, F.: Ice-sheet modelling at different spatial resolutions: focus on the grounding line, Ann. Glaciol., 31, 211-216, 2000.

Pattyn, F.: Transient glacier response with a higher-order numerical ice-flow model, J. Glaciol., 48, 467-477, 2002.

Pattyn, F.: A New 3D Higher-Order Thermomechanical Ice-Sheet Model: Basic Sensitivity, Ice-Stream Development and Ice Flow across Subglacial Lakes, J. Geophys. Res., 108, B82382, doi:10.1029/2002JB002329, 2003.

Pattyn, F. and Derauw, D.: Ice-dynamic conditions of Shirase Glacier, Antarctica, inferred from ERS-SAR interferometry, J. Glaciol., 48, 559-565, 2002.

Pattyn, F., Perichon, L., Aschwanden, A., Breuer, B., de Smedt, B., Gagliardini, O., Gudmundsson, G. H., Hindmarsh, R. C. A., Hubbard, A., Johnson, J. V., Kleiner, T., Konovalov, Y., Martin, C., Payne, A. J., Pollard, D., Price, S., Rückamp, M., Saito, F., Souček, O., Sugiyama, S., and Zwinger, T.: Benchmark experiments for higher-order and full-Stokes ice sheet models (ISMIPHOM), The Cryosphere, 2, 95-108, doi:10.5194/tc-2-95-2008, 2008.

Pattyn, F., Matsuoka, K., Callens, D., Conway, H., Depoorter, M., Docquier, D., Hubbard, B., Samyn, D., and Tison, J. L.: Melting and refreezing beneath Roi Baudouin Ice Shelf (East Antarctica) 
inferred from radar, GPS, and ice core data, J. Geophys. Res., 117, F04008, doi:10.1029/2011JF002154, 2012

Pritchard, H. D., Ligtenberg, S. R. M., Fricker, H. A., Vaughan, D. G., van den Broeke, M. R., and Padman, L.: Antarctic ice-sheet loss driven by basal melting of ice shelves, Nature, 484, 502-505, doi:10.1038/nature10968, 2012.

Rabus, B. T. and Echelmeyer, K. A.: The Flow of a Polythermal Glacier: McCall Glacier, Alaska, U.S.A., J. Glaciol., 43, 522536, 1997.

Rapp, R. H.: Use of potential coefficient models for geoid undulation determinations using a spherical harmonic representation of the height anomaly/geoid undulation difference, J. Geodesy, 71, 282-289, 1997.

Rignot, E., Bamber, J. L., van den Broeke, M. R., Davis, C., Li, Y., van de Berg, W. J., and van Meijgaard, E.: Recent Antarctic ice mass loss from radar interferometry and regional climate modelling, Nat. Geosci., 1, 106-110, 2008.

Rignot, E., Mouginot, J., and Scheuchl, B.: Ice flow of the Antarctic ice sheet, Science, 333, 1427-1430, 2011a.

Rignot, E., Mouginot, J., and Scheuchl, B.: MEaSUREs Antarctic Grounding Line from Differential Satellite Radar Interferometry, NASA EOSDIS Distributed Active Archive Center at NSIDC, Boulder, Colorado, USA, Digital media, 2011b.

Rignot, E., Jacobs, S., Mouginot, J., and Scheuchl, B.: Ice shelf melting around Antarctica, Science, 314, 266-270, 2013.

Rippin, D. M., Vaughan, D. G., and Corr, H. F. J.: The basal roughness of Pine Island Glacier, West Antarctica, J. Glaciol., 57, 6776, 2011.

SCAR: Scientific Committee on Antarctic Research Antarctic Digital Database, available at: http://www.add.scar.org (last access: 6 July 2012), digital media, 2012.

Schoof, C.: Ice sheet grounding line dynamics: steady states, stability and hysteresis, J. Geophys. Res., 112, F03S28, doi:10.1029/2006JF000664, 2007.
Schoof, C.: Glaciology: beneath a floating ice shelf, Nat. Geosci., $3,450-451,2010$.

Shepherd, A., Ivins, E. R., Geruo, A., Barletta, V. R., Bentley, M. J., Bettadpur, S., Briggs, K. H., Bromwich, D. H., Forsberg, R., Galin, N., Horwath, M., Jacobs, S., Joughin, I., King, M. A., Lenaerts, J. T. M., Li, J., Ligtenberg, S. R. M., Luckman, A., Luthcke, S. B., McMillan, M., Meister, R., Milne, G., Mouginot, J., Muir, A., Nicolas, J. P., Paden, J., Payne, A. J., Pritchard, H., Rignot, E., Rott, H., Sandberg Sørensen, L., Scambos, T. A., Scheuchl, B., Schrama, E. J. O., Smith, B., Sundal, A. V., van Angelen, J. H., van de Berg, W. J., van den Broeke, M. R., Vaughan, D. G., Velicogna, I., Wahr, J., Whitehouse, P. L., Wingham, D. J., Yi, D., Young, D., and Zwally, H. J.: A reconciled estimate of ice-sheet mass balance, Science, 338 , 1183-1189, 2012.

Smedsrud, L. H., Jenkins, A., Holland, D. M., and Nøst, O. A.: Modeling ocean processes below Fimbulisen, Antarctica, J. Geophys. Res., 111, C01007, doi:10.1029/2005JC002915, 2006.

Steinhage, D., Nixdorf, U., Meyer, U., and Miller, H.: Subglacial topography and internal structure of central and western Dronning Maud Land, Antarctica, determined from airborne radio echo sounding, J. Appl. Geophys., 47, 183-189, 2001.

Taylor, J., Siegert, M., Payne, A., and Hubbard, B.: Regional-scale bed roughness beneath ice masses: measurement and analysis, Comput. Geosci., 30, 899-908, 2004.

Timmermann, R., Le Brocq, A., Deen, T., Domack, E., Dutrieux, P., Galton-Fenzi, B., Hellmer, H., Humbert, A., Jansen, D., Jenkins, A., Lambrecht, A., Makinson, K., Niederjasper, F., Nitsche, F., Nøst, O. A., Smedsrud, L. H., and Smith, W. H. F.: A consistent data set of Antarctic ice sheet topography, cavity geometry, and global bathymetry, Earth Syst. Sci. Data, 2, 261-273, doi:10.5194/essd-2-261-2010, 2010. 